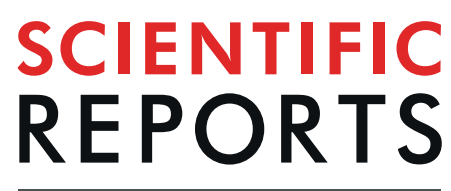

natureresearch

Check for updates

\title{
Establishment of 2.5D organoid culture model using 3D bladder cancer organoid culture
}

Amira Abugomaa ${ }^{1,2,13}$, Mohamed Elbadawy ${ }^{1,3,13}$, Megumi Yamanaka ${ }^{1}$, Yuta Goto ${ }^{1}$, Kimika Hayashi ${ }^{1}$, Takashi Mori ${ }^{4,5}$, Tsuyoshi Uchide ${ }^{6}$, Daigo Azakami ${ }^{7}$, Ryuji Fukushima ${ }^{8}$, ToshinoriYoshida ${ }^{9}$, Makoto Shibutani ${ }^{9}$, Risako Yamashita ${ }^{9}$, Mio Kobayashi ${ }^{9}$, Hideyuki Yamawaki ${ }^{10}$, Yuta Shinohara ${ }^{1,11}$, Masahiro Kaneda ${ }^{12}$, Tatsuya Usui ${ }^{1 凶}$ \& Kazuaki Sasaki ${ }^{1}$

Three-dimensional (3D) organoid culture holds great promises in cancer precision medicine. However, Matrigel and stem cell-stimulating supplements are necessary for culturing 3D organoid cells. It costs a lot of money and consumes more time and effort compared with 2D cultured cells. Therefore, the establishment of cheaper and Matrigel-free organoid culture that can maintain the characteristics of a part of 3D organoids is demanded. In the previous study, we established a dog bladder cancer (BC) 3D organoid culture system by using their urine samples. Here, we successfully isolated cells named "2.5D organoid" from multiple strains of dog BC 3D organoids using 2.5 organoid media. The cell proliferation speed of 2.5D organoids was faster than parental 3D organoid cells. The expression pattern of stem cell markers was close to 3D organoids. Injection of 2.5D organoid cells into immunodeficient mice formed tumors and showed the histopathological characteristics of urothelial carcinoma similar to the injection of dog BC 3D organoids. The 2.5D organoids had a similar sensitivity profile for anti-cancer drug treatment to their parental 3D organoids. These data suggest that our established 2.5D organoid culture method might become a reasonable and useful tool instead of $3 \mathrm{D}$ organoids in dog $\mathrm{BC}$ research and therapy.

Bladder cancer (BC), also known as transitional cell carcinoma (TCC) or urothelial carcinoma, is the most frequent form of urinary BC in dogs, affecting thousands of dogs annually worldwide ${ }^{1}$. It constitutes approximately $1-2 \%$ of all naturally occurring cancers in dogs, a nearly similar rate to humans ${ }^{2,3}$. The majority of $\operatorname{dog} \mathrm{BC}$ is high grade invasive urothelial carcinoma ${ }^{2,4,5}$. In addition to the late diagnosis of dog $\mathrm{BC}$, it is very difficult to treat them $^{6,7}$. Although several experimental models of BC by using mouse and rat were developed ${ }^{8-10}$, they hardly reflect the characteristics of invasive or metastatic human $\mathrm{BC}^{11}$ and the mechanism of its arising and development

\footnotetext{
${ }^{1}$ Laboratory of Veterinary Pharmacology, Department of Veterinary Medicine, Faculty of Agriculture, Tokyo University of Agriculture and Technology, 3-5-8 Saiwai-cho, Fuchu, Tokyo, 183-8509, Japan. ${ }^{2}$ Faculty of Veterinary Medicine, Mansoura University, 35516, Mansoura, Egypt. ${ }^{3}$ Department of Pharmacology, Faculty of Veterinary Medicine, Benha University, 13736, Moshtohor, Toukh, Egypt. 'Laboratory of Veterinary Clinical Oncology, Faculty of Applied Biological Sciences, Gifu University, 1-1, Yanagido, Gifu, Gifu, 501-1193, Japan. ${ }^{5}$ Center for Highly Advanced Integration of Nano and Life Sciences, Gifu University (G-CHAIN), 1-1, Yanagido, Gifu, Gifu, 501-1193, Japan. ${ }^{6}$ Department of Veterinary Surgery, Faculty of Agriculture, Tokyo University of Agriculture and Technology, 35-8 Saiwai-cho, Fuchu, Tokyo, 183-8509, Japan. ${ }^{7}$ Department of Veterinary Clinical Oncology, Faculty of Agriculture, Tokyo University of Agriculture and Technology, 3-5-8 Saiwai-cho, Fuchu, Tokyo, 183-8509, Japan. ${ }^{8}$ Animal Medical Center, Faculty of Agriculture, Tokyo University of Agriculture and Technology, 3-5-8 Saiwai-cho, Fuchu, Tokyo, 183-8509, Japan. ${ }^{9}$ Laboratory of Veterinary Pathology, Department of Veterinary Medicine, Faculty of Agriculture, Tokyo University of Agriculture and Technology, 3-5-8 Saiwai-cho, Fuchu, Tokyo, 183-8509, Japan. ${ }^{10}$ Laboratory of Veterinary Pharmacology, School of Veterinary Medicine, Kitasato University, 35-1 Higashi 23 ban-cho, Towada, Aomori, 034-8628, Japan. ${ }^{11}$ Pet Health \& Food Division, Iskara Industry CO., LTD, 1-14-2, Nihonbashi, Chuo-ku, Tokyo, 103-0027, Japan. ${ }^{12}$ Laboratory of Veterinary Anatomy, Department of Veterinary Medicine, Faculty of Agriculture, Tokyo University of Agriculture and Technology, 3-5-8 Saiwai-cho, Fuchu, Tokyo, 183-8509, Japan. ${ }^{13}$ These authors contributed equally: Amira Abugomaa and Mohamed Elbadawy. ${ }^{凶}$ e-mail: fu7085@go.tuat.ac.jp
} 


\begin{tabular}{|l|l|l|}
\hline Supplement & 2.5D organoid & 3D organoid \\
\hline Wnt, Noggin and R-Spondin & - & + \\
\hline FBS & + & - \\
\hline EGF & + & + \\
\hline GlutaMax & + & + \\
\hline N-Acetyl-l-cysteine & + & + \\
\hline Nicotinamide & + & + \\
\hline A83-01 & + & + \\
\hline HEPES & + & + \\
\hline Antibiotics & + & + \\
\hline
\end{tabular}

Table 1. The difference of media components between $2.5 \mathrm{D}$ and 3D organoid culture.

\begin{tabular}{|l|l|l|l|l|}
\hline Case ID & $\begin{array}{l}\text { Age } \\
\text { (year old) }\end{array}$ & Breed & Sex & Sample Date \\
\hline $\begin{array}{l}\text { BC18004 (used } \\
\text { as BC1) }\end{array}$ & 12 & Miniature Dachshund & Female (spayed) & $2018 / 5 / 2$ \\
\hline $\begin{array}{l}\text { BC18005 (used } \\
\text { as BC2) }\end{array}$ & 11 & Mix & Female (spayed) & $2018 / 5 / 11$ \\
\hline $\begin{array}{l}\text { BC19004 (used } \\
\text { as BC3) }\end{array}$ & 11 & Maltese & Female (not spayed) & $2019 / 8 / 2$ \\
\hline
\end{tabular}

Table 2. Sample information.

still remains obscure. Interestingly, the naturally arising dog BC closely mimics invasive BC in human in the cellular and molecular features like histopathological architecture, local invasion, distant metastases, chemotherapy response, and prognosis ${ }^{7}$, suggesting that $\operatorname{dog} \mathrm{BC}$ might be a pertinent model of invasive $\mathrm{BC}$ in human.

Three-dimensional (3D) organoid culture is derived from self-renewing stem cells that typically recapitulate the in vivo architecture, functions, and genetic and molecular imprints of their original tissues. It holds great promise for use in medical research for establishing novel personalized therapies, especially cancer ${ }^{12,13}$.

In the previous study, we established the 3D culture method of dog $\mathrm{BC}$ organoids using the urine samples from $\mathrm{BC}$ diseased dogs ${ }^{14}$. The organoids recapitulated the tumor microenvironment of their parental tumor tissues and showed tumorigenesis in vivo. Furthermore, it could be used to investigate the sensitivity of anti-cancer drugs and their combinations. However, using the $3 \mathrm{D}$ organoid culture method for experiments costs a lot of money due to the expensive gel and the stem cell-stimulating supplements contained in the culture media. It also needs a long time because of the complicated handling (dissolving and solidifying gel) and the slow growth speed of the organoid cells compared with 2D cell lines. Although there is a need to establish a cheaper and easier-to-use organoid culture method, an alternative to the 3D organoid culture method has not been fully developed.

In the present study, we hypothesized that some media components enable patient-derived 3D organoid cells to culture in Matrigel-free 2D culture conditions without losing their characteristics such as marker expression, stemness, and drug sensitivity of their original 3D organoids (we named the cells $2.5 \mathrm{D}$ organoids). Here, we identified the suitable media components for culturing 2.5D organoids and established a new culture method of dog BC 2.5D organoids from different strains of dog BC 3D organoids. Since these $2.5 \mathrm{D}$ organoids partially exhibited similar characteristics to their parental 3D organoids, we expect that they could be useful as a new experimental tool not only in dogs but also in human BC research.

\section{Materials and Methods}

Materials. To isolate $2.5 \mathrm{D}$ organoids from 3D organoids, we used a special $2.5 \mathrm{D}$ organoid media. The components were as follows: Advanced Dulbecco's Modified Eagle's Medium (DMEM)/F12 (Thermo Fisher Scientific Inc., Waltham, MA, USA) supplemented with $10 \mathrm{mM} \mathrm{4-(2-hydroxyethyl)-1-piperazineethanesulfonic} \mathrm{acid}$ (HEPES;WAKO, Osaka, Japan), 1\% GlutaMax (Thermo Fisher Scientific Inc), $10 \mathrm{mM}$ Nicotinamide (SigmaAldrich, St. Louis, MO, USA), 1 mM N-acetyl-L-cysteine (Sigma-Aldrich), 0.5 $\mu$ M A83-01 (Adooq Bioscience, Irvine, CA, USA), 1\% penicillin-streptomycin (PS; WAKO), and 5\% fetal bovine serum (FBS; Thermo Fisher Scientific Inc.). The difference of culture supplements between 2.5D and 3D organoid was shown in Table 1. Anti-cancer drugs were as follows: vinblastine, mitoxantrone (Cayman, Ann Arbor, MI, USA), and carboplatin (WAKO). The used antibodies were as follows: CK5 (GeneTex, Inc., Irvine, CA, USA), CK7 (Novus, Centennial, CO, USA); CK20 and UPK3A (Bioss, Woburn, MA, USA). Fluorescent secondary antibodies were as follows: Alexa Fluor 488 goat anti-rabbit IgG; Alexa Fluor 488 goat anti-mouse IgG; (Thermo Fisher Scientific Inc.). Dog urothelial carcinoma cell lines were purchased from COSMO BIO CO., Ltd (Tokyo, Japan), and cultured in DMEM containing 10\% FBS (Thermo Fisher Scientific Inc.) and 1\% Penicillin-Streptomycin (PS) (WAKO).

Generation of dog BC 2.5D organoids. In the previous study, we generated urine sample-derived dog BC 3D organoids ${ }^{14}$. Using our established 3 strains of BC organoids (Table 2), we generated 2.5D organoids in the present study. Each dog 3D organoid cell was treated with 2.5D organoid media and cultured for 3-7 days. After the migrated cells from organoids attached the bottom of the plate, Matrigel containing organoids was stripped and $500 \mu \mathrm{L}$ of $5 \mathrm{mM}$ ethylenediaminetetraacetic acid (EDTA)/ Phosphate Buffered Saline (PBS) was added per 


\begin{tabular}{|l|l|l|}
\hline $\begin{array}{l}\text { Gene } \\
\text { name }\end{array}$ & Primer & Sequence \\
\hline \multirow{2}{*}{ SOX2 } & Forward & $5^{\prime}$-GCCCTGCAGTACAACTCCAT-3' \\
\cline { 2 - 3 } & Reverse & $5^{\prime}$-GGAGTGGGAGGAGGAGGTAA-3' \\
\hline \multirow{2}{*}{ CD44 } & Forward & $5^{\prime}$-CCAAGACAGTTCCAGGGTGT-3' \\
\cline { 2 - 3 } & Reverse & $5^{\prime}$-TTGAGGTTTCCGCATAGGAC-3' \\
\hline \multirow{2}{*}{ GAPDH } & Forward & 5'-AACTCCCTCAAGATTGTCAGCAA-3' $^{\prime}$ \\
\cline { 2 - 3 } & Reverse & $5^{\prime}$-CATGGATGACTTTGGCTAGAGGA-3' \\
\hline
\end{tabular}

Table 3. Primers for real-time quantitative PCR analysis.

well for $10 \mathrm{~min}$ at $37^{\circ} \mathrm{C}$ in a $\mathrm{CO}_{2}$ incubator. The EDTA solution in each well was collected in a $15 \mathrm{ml}$ tube and centrifuged at $600 \mathrm{~g}$ for $5 \mathrm{~min}$. After the cell pellet was trypsinized for $3 \mathrm{~min}$, they were seeded in $6 \mathrm{~cm}$ dishes with our prepared 2.5D organoid media. Media were changed three times a week. The present study was conducted under the institutional Animal Care and Use Committee of Tokyo University of Agriculture and Technology approval (Approval number: 0016012).

Passaging of dog BC 2.5D organoids. After $70-80 \%$ confluent conditions, $2.5 \mathrm{D}$ organoid cells were passaged into a new $6 \mathrm{~cm}$ dish at a ratio of 1:3-4. To collect cells, $1 \mathrm{~mL}$ of $5 \mathrm{mM}$ EDTA/PBS was added, and the culture dish was placed at $\mathrm{CO}_{2}$ incubator at $37^{\circ} \mathrm{C}$ for $10 \mathrm{~min}$. Thereafter, the EDTA solution was collected. Subsequently, $1 \mathrm{~mL}$ TrypLE Express solution (Thermo Fisher Scientific Inc.) was added to the cell pellets and they were incubated at $37^{\circ} \mathrm{C}$ for $3-5 \mathrm{~min}$. The trypsinized cell suspension was vigorously pipetted and collected into a $15 \mathrm{~mL}$ tube containing $100 \mu \mathrm{l} \mathrm{FBS}$ and then centrifuged at $600 \mathrm{~g}$ for $3 \mathrm{~min}$. Cell pellets were mixed with new 2.5D organoid media and seeded into a $6 \mathrm{~cm}$ dish. We defined the passaged cells as early (4-8) and late passage (15-20) cells.

Comparison of culture efficiency between 2.5D organoid media and 2D cell line media. After the isolated $2.5 \mathrm{D}$ organoid cells were seeded into $6 \mathrm{~cm}$ dishes, they were cultured with $2.5 \mathrm{D}$ organoid media or $2 \mathrm{D}$ cell line media (DMEM containing $10 \%$ FBS and 1\% PS) to compare the efficiency of cell attachment and proliferation after passaging. The bright-field images were obtained using a light microscope (BX-52; Olympus, Tokyo, Japan).

Immunofluorescence staining of 2.5D organoids. Immunofluorescence staining of BC 2.5D organoids was performed as described before ${ }^{14,15}$. Briefly, the $2.5 \mathrm{D}$ cells $\left(2 \times 10^{5} /\right.$ well $)$ were seeded on a coverslip in a 6 -well plate. After $70 \%$ confluent conditions, the cells were fixed with $4 \%$ paraformaldehyde (PFA) solution for 10 min. Later, the cells were exposed to $0.2 \%$ Triton X/PBS for a few seconds. Blocking was done using 3\% skimmed milk/ PBS for $1 \mathrm{~h}$. Subsequently, cells were treated with the primary antibodies (CK5; 1:200, CK7;1:50, CK20;1:200, and UPK3A;1:200) and kept at $4{ }^{\circ} \mathrm{C}$ overnight. After they were treated with the secondary antibodies and DAPI solution (1:1000) for $1 \mathrm{~h}$ at room temperature, the expressions were examined using a confocal microscope (LSM 800; ZEISS, Copenhagen, Germany).

Cell proliferation assay. After an equal number of 2.5D organoid cells at early and late passages and 3D organoid cells were seeded in 96 -well plate at a density of $2 \times 10^{3}$ cells/well, each cell was cultured for 5 days. The number of living cells at day 1, 3 and 5 was evaluated by using a Prestoblue kit (Thermo Fisher Scientific Inc.). The fluorescence intensity was measured by a microplate reader (TECAN, Seestrasse, Switzerland) at an emission wavelength of $585 \mathrm{~nm}$.

Quantitative real-time PCR. Quantitative real-time PCR was performed as described previously ${ }^{14}$. Total RNA was extracted from $2 \times 10^{5}$ of $2.5 \mathrm{D}$ organoid cells at early and late passage, 3D organoids, and urothelial carcinoma cell lines by using a NucleoSpin kit (Takara Bio Inc., Shiga, Japan) following the manufacturer's protocol. First-strand cDNA was prepared using a QuantiTect Reverse Transcription Kit (TOYOBO, Tokyo, Japan). Quantitative real-time PCR was done using a QuantiTect SYBR I Kit (QIAGEN, Hilden, Germany) and a StepOnePlus Real-Time PCR System (Applied Biosystems, Waltham, MA, USA). The $\Delta \Delta$ Cq method was used for quantification. Specific primers used for dog BC stem cell markers, SOX2, CD44, and GAPDH were designed and are shown in Table 3.

Mouse xenograft assay. Mouse xenograft assay of $2.5 \mathrm{D}$ organoids was carried out as previously described ${ }^{14,15}$. Four NSG male immunodeficient mice ( 6 weeks old) were obtained from Japan SLC (Shizuoka, Japan). They were housed under strict pathogen-free conditions. Here, $1 \times 10^{6} 2.5 \mathrm{D}$ organoid cells were subcutaneously injected into the back of mice. Six weeks later, the $2.5 \mathrm{D}$ organoid-derived tumors were dissected under isoflurane anesthesia and used for $\mathrm{H} \& \mathrm{E}$ and immunofluorescence staining. All animal experiments in the present study were performed following the Guide to Animal Use and Care of Tokyo University of Agriculture and Technology and approved by the ethics committee (Approval number: 29-92).

H\&E staining of xenografted tumor tissues. H\&E staining of 2.5D organoid-derived tumor tissues was performed as described previously ${ }^{14,15}$. After the isolated tumor tissues were fixed with $4 \%$ PFA for $24 \mathrm{~h}$, they 
were embedded in paraffin. After deparaffinization, $4 \mu \mathrm{m}$-thick sections were stained with H\&E. The images were obtained using a light microscope (BX-52; Olympus).

Sensitivity of 2.5D organoids to anti-cancer drugs. Cell viability assay of the $2.5 \mathrm{D}$ organoid cells at early and late passages compared with their original 3D organoid ones was carried out as described before ${ }^{14}$. Briefly, $1 \times 10^{3}$ cells of each $2.5 \mathrm{D}$ cells or $2 \times 10^{3}$ of their $3 \mathrm{D}$ organoid single cells were seeded in 96-well culture plates and incubated in a $\mathrm{CO}_{2}$ incubator at $37^{\circ} \mathrm{C}$ for $24 \mathrm{~h}$. The cells were treated with anti-cancer drugs including a microtubule inhibitor, vinblastine $(0.01-10 \mathrm{nM})$, a topoisomerase inhibitor, mitoxantrone $(0.1-100 \mathrm{ng} / \mathrm{mL})$, or a DNA-damaging agent, carboplatin $(0.1-100 \mu \mathrm{g} / \mathrm{mL})$ for $72 \mathrm{~h}$. Cell viabilities of the 3D and $2.5 \mathrm{D}$ organoid cells were examined in the same way as in the cell proliferation assay.

Statistical analysis. The obtained data were presented as means \pm SEM. Statistical assessments were carried out using the one-way analysis of variance (ANOVA) method followed by Bonferroni's test. Statistical significance was considered when $P$-values $\leq 0.05$.

\section{Results}

Generation of dog bladder cancer (BC) 2.5D organoids. In the previous study, we established a novel method of 3D organoid culture from BC diseased dogs using their urine samples ${ }^{14}$. Our established BC 3D organoids expressed urothelial markers (CK7, CK20, and UPK3A), showed the response to anti-cancer drugs, and exhibited tumorigenesis. In the present study, we hypothesized that some media components enable 3D organoid cells to culture in gel-free 2D culture conditions without losing their characteristics such as marker expression, stemness, and drug sensitivity. To prove the hypothesis, we made original media and checked whether the media efficiently generates 3D organoid-derived $2 \mathrm{D}$ cells $(2.5 \mathrm{D}$ organoid) and can keep the characteristics (Fig. 1A). After treating 3D organoid cells with the media for a few days, cells gradually migrated from organoids and adhered to the bottom of the plate (Fig. 1B). We purely isolated the adhered cells and cultured them in $2.5 \mathrm{D}$ organoid media. The $2.5 \mathrm{D}$ organoid cells were successfully passaged and propagated over passage 10 (Fig. 1B). We also confirmed that $2.5 \mathrm{D}$ organoids can be isolated from different strains of dog BC 3D organoids (Fig. 1C). The cells have a cobblestone- and fibroblast-like appearance (Fig. 1C), similarly to urothelial carcinoma cell lines ${ }^{16}$. To prove the utility of 2.5D organoid media, we compared the cell attachment and growth between 2.5D organoid and normal cell line media (Fig. 1D). The isolated 2.5D organoid cells cultured in 2.5D organoid media showed a better cell attachment and proliferation than normal cell line media (Fig. 1D). Further, we tried to generate 2.5D organoids directly from urine samples without going through 3D organoids. However, the cells did not proliferate well (data not shown), suggesting that the generation of $3 \mathrm{D}$ organoids at first is a necessary step for generating $2.5 \mathrm{D}$ ones.

Expression of urothelial markers in BC 2.5D organoids. To identify the characterization of BC 2.5D organoid cells, we investigated the expression of urothelial markers (CK7, CK20, and UPK3A). The 2.5D organoid cells (both early and late passages) expressed urothelial cell markers, CK7, CK20, and UPK3A (Fig. 2A) similar to the original $\mathrm{BC} 3 \mathrm{D}$ organoids ${ }^{14}$.

Cell proliferation speed in BC 2.5D organoids. After seeding equal numbers of 2.5D organoid cells at early and late passages as well as their original 3D organoids, living cell number was evaluated by Prestoblue assay. The $2.5 \mathrm{D}$ organoid cells at early and late passages showed a significantly accelerated proliferation rate at day 5 compared with their original 3D organoids (Fig. 2B).

Expression of basal cell marker in BC 2.5D organoids. To check whether a basal cell marker was expressed in $2.5 \mathrm{D}$ organoids, we investigated the expression of a basal marker, CK5. The 2.5D organoid cells expressed CK5 similarly to the parental 3D organoids (Fig. 2C).

Plasticity of BC 2.5D organoids. To check whether 2.5D organoids can revert to 3D organoids, we collected the generated 2.5D organoid cells and embedded them into Matrigel again. The 2.5D organoid cells were successfully reverted to 3D organoids (Fig. 2D), which were continually expanded after passaging, indicating that $2.5 \mathrm{D}$ organoid cells maintain the stemness property and possess the plasticity.

Expression pattern of cancer stem cell markers, SOX2 and CD44 in BC 2.5D organoids. Since $3 \mathrm{D}$ organoids contain many stem cells compared with 2D cultured cells, we investigated whether BC $2.5 \mathrm{D}$ organoids maintain the expression level of stem cell markers as an indicator of stemness. Among 3D organoid, 2.5D early passage organoid, 2.5D late passage organoid, and urothelial carcinoma cell line, mRNA expression level of SOX2 was the highest in 3D organoid (Fig. 3A). In both $2.5 \mathrm{D}$ early passage and $2.5 \mathrm{D}$ late passage organoids, mRNA expression of SOX2 was a little bit lower compared with 3D organoids but much higher than cell lines (Fig. 3A). Interestingly, mRNA expression level of CD44 was the highest in cell line. In both early and late passages of BC 2.5D organoids, expression level of CD44 was quite lower similar to the parental 3D organoid (Fig. 3A). In another strain of BC organoid, we confirmed that stem cell marker expression showed the similar trend (Fig. 3B). These results suggest that $2.5 \mathrm{D}$ organoids could keep the characteristic of stemness in $3 \mathrm{D}$ organoids.

Tumorigenesis induced by BC 2.5D organoids. In the previous study, we demonstrated that urine sample-derived BC organoids formed a tumor in vivo ${ }^{14}$. We therefore checked the tumorigenesis of the 2.5D organoids in vivo. After subcutaneous injection of the $2.5 \mathrm{D}$ cells into the back of immunodeficient mice, tumors of less than $1 \mathrm{~cm}$ in diameter were successfully formed after 6 weeks (Fig. 4A). Additionally, H\&E staining of the formed tumors showed the histopathology of typical urothelial carcinoma (Fig. 4B). To characterize the cellular 
A

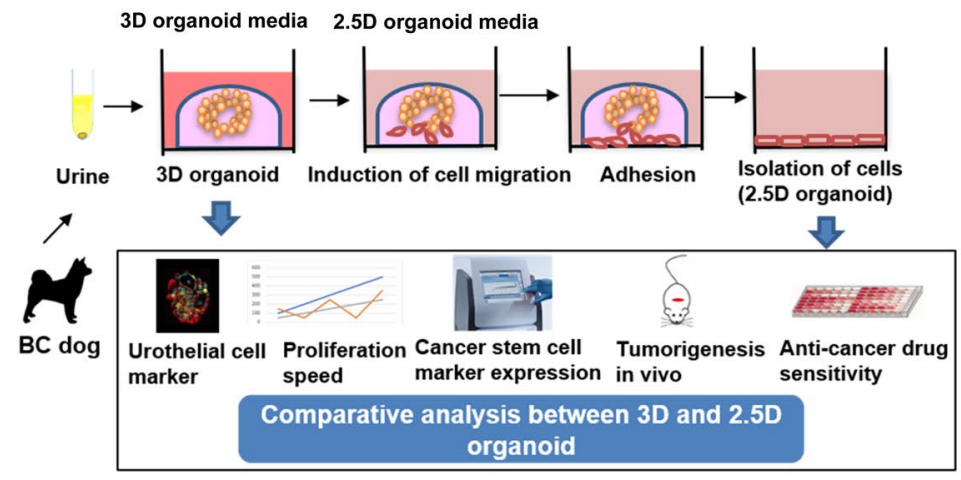

B

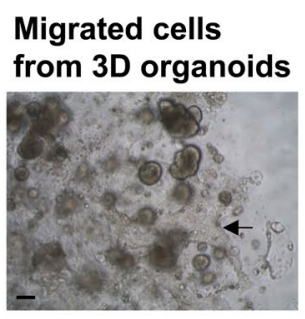

Passage 1

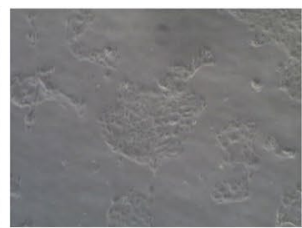

C

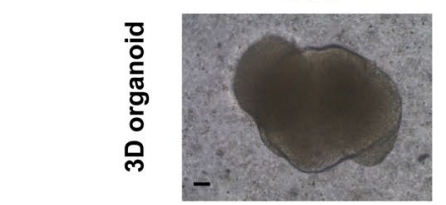

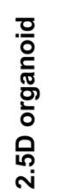

D
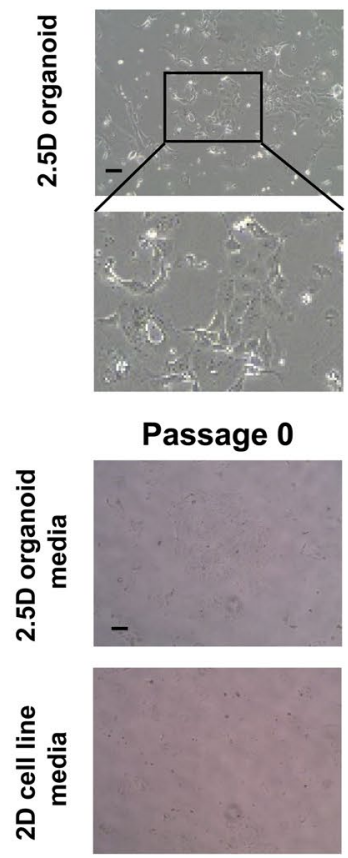

Passage 3

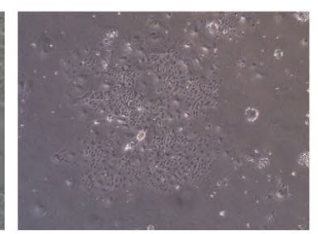

BC2
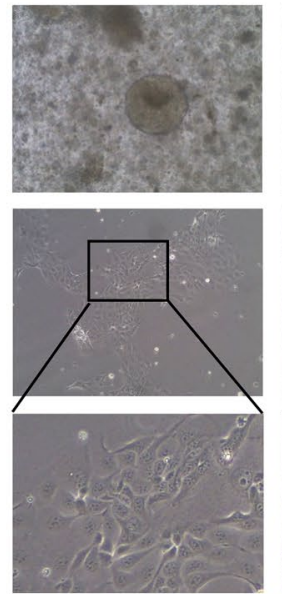

Passage 1
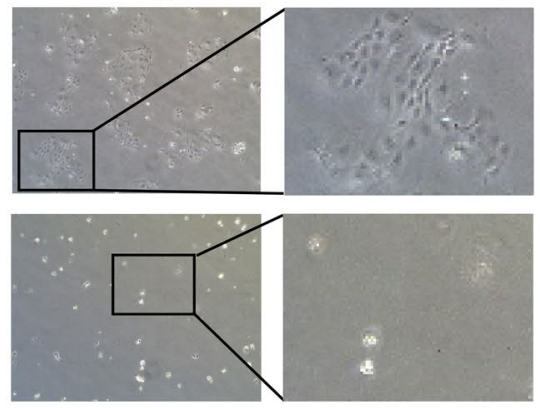

Figure 1. Generation of dog bladder cancer (BC) 2.5D organoids. Schematic experimental design of a procedure for isolation of $2.5 \mathrm{D}$ organoid cells from $3 \mathrm{D}$ organoids and the analysis overview (A). Representative bright-field images of the process of generation of $2.5 \mathrm{D}$ organoids from $3 \mathrm{D}$ ones and serially passaged cells (B). Scale bar: $500 \mu \mathrm{m}$. Representative images and enlarged ones (Scale bar: $200 \mu \mathrm{m}$ ) for three different strains of 2.5D organoid cells and their parental 3D organoids (C). Comparison of cell attachment and proliferation between the $2.5 \mathrm{D}$ organoid media and 2D cell line media (D). Representative images at passage 0 and 1 and enlarged ones at passage 1 were shown. Scale bar: $500 \mu \mathrm{m}$.

components of the isolated tumor tissues, immunofluorescence staining was carried out and expression of CK7, CK20, and UPK3A was observed in the tumor tissues (Fig. 4C). These findings suggest that BC 2.5D organoids maintained the ability to form tumors in vivo similar to BC 3D organoids. 
A
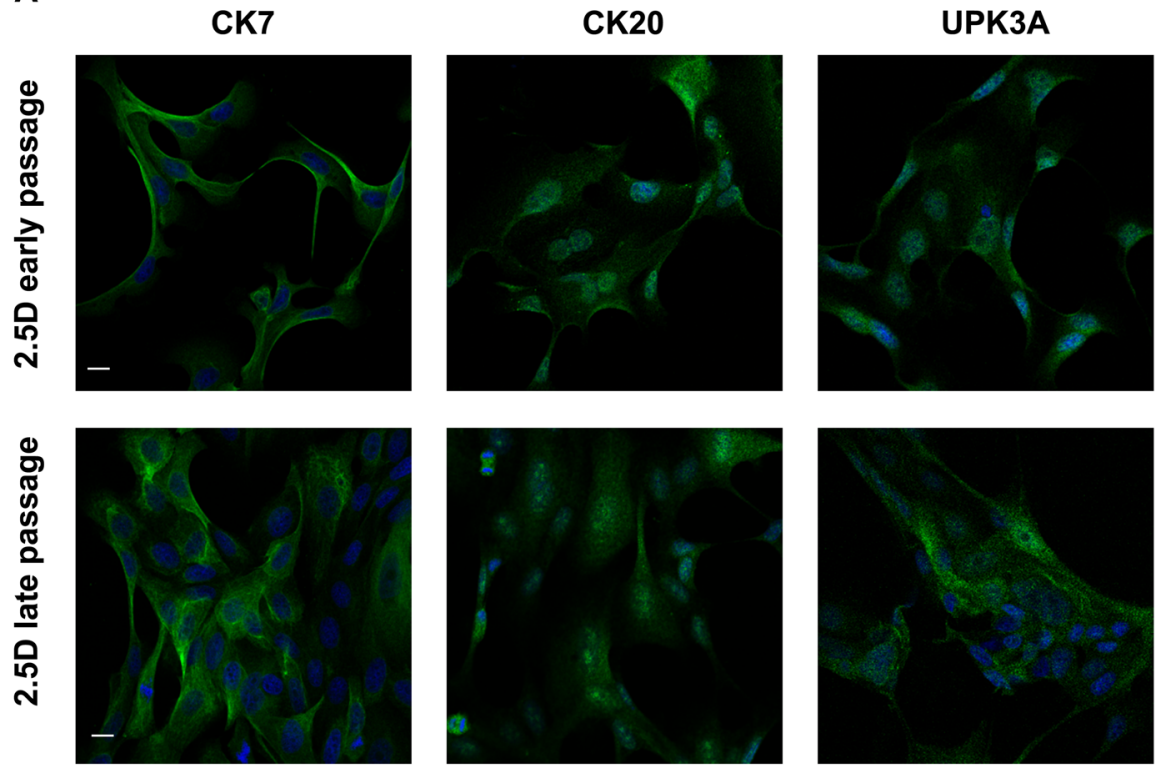

B

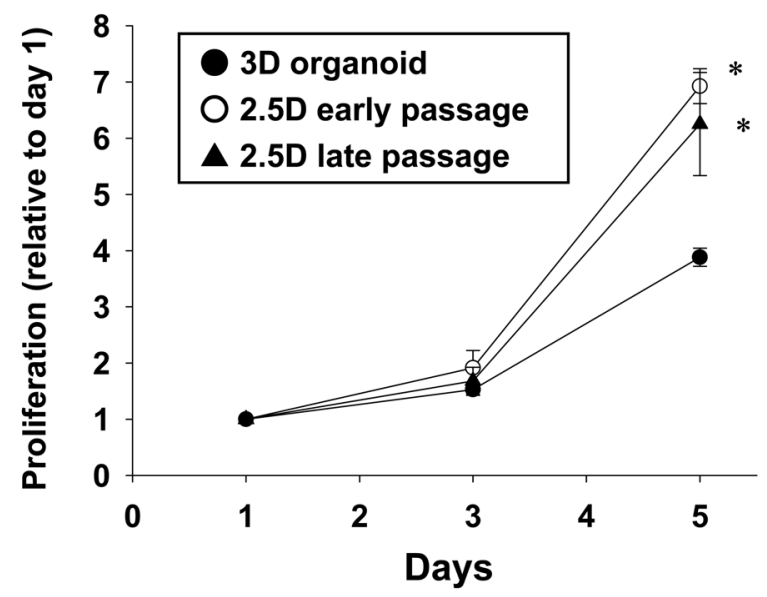

C
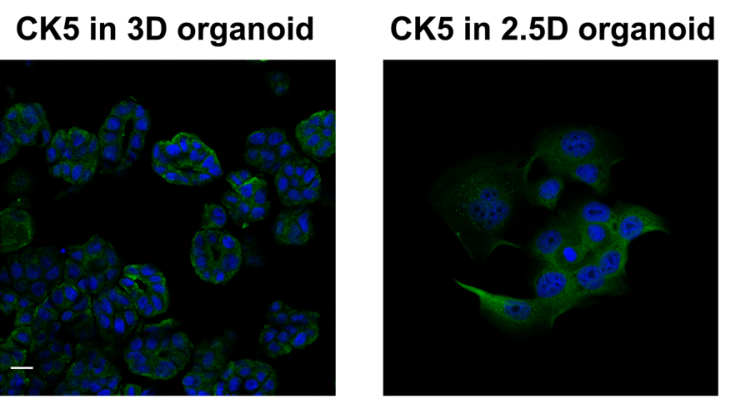

$\mathbf{D}$
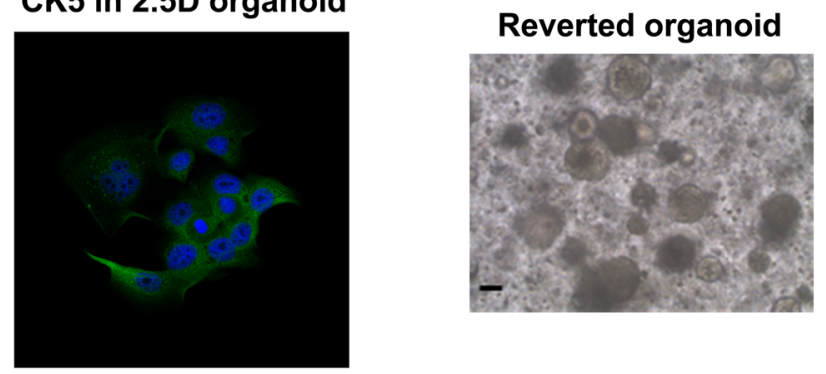

Figure 2. Characterization of BC 2.5D organoids. Expression of urothelial cell markers, CK7, CK20, and UPK3A in 2.5D organoid cells at early (4-8) and late passages (15-20) $(A, n=4)$. Scale bar: $50 \mu \mathrm{m}$. Comparison of cell proliferation at day 1,3 , and 5 between $2.5 \mathrm{D}$ organoid at the early and late passage and their original $3 \mathrm{D}$ organoid. Cell proliferation was assayed by Prestoblue cell viability reagent and shown as fold increase relative to day 1 (B, $\mathrm{n}=6$ ). Results were expressed as mean \pm S.E.M. $* P<0.05$ vs. $3 \mathrm{D}$ organoid. Expression of a basal cell marker, CK5 in the $2.5 \mathrm{D}$ organoid cells and parental 3D organoids $(C, n=4)$. Scale bar: $50 \mu \mathrm{m}$. Plasticity of BC 2.5D organoids. Representative bright-field images of the reverted 3D organoids from $2.5 \mathrm{D}$ ones (D). Scale bar: $200 \mu \mathrm{m}$. 
A

\section{sox2}

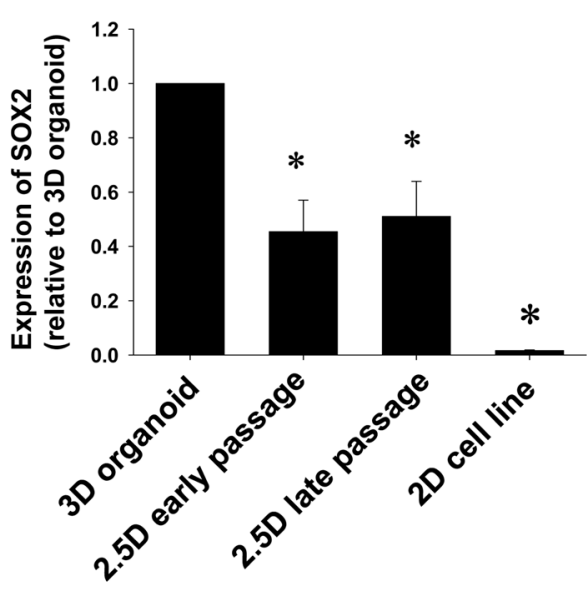

CD44

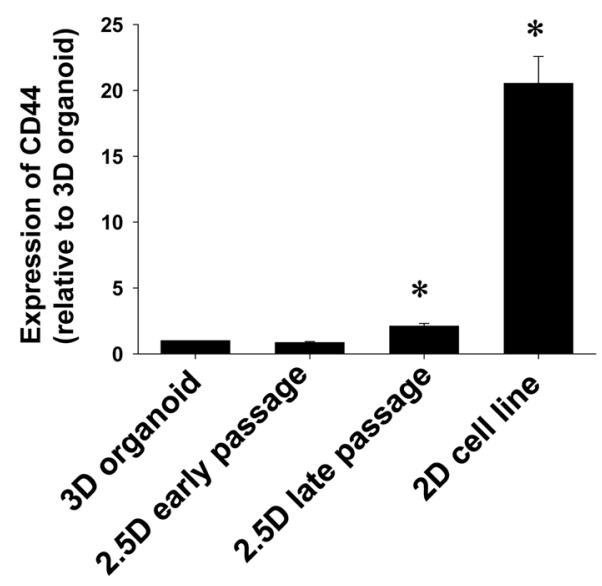

B

\section{sox2}

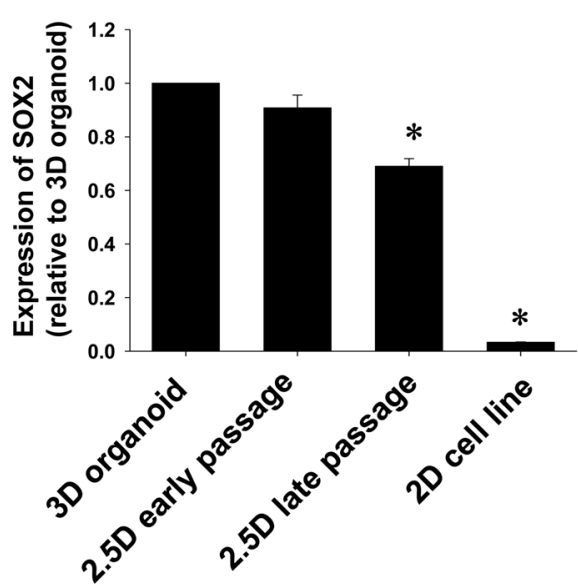

\section{CD44}

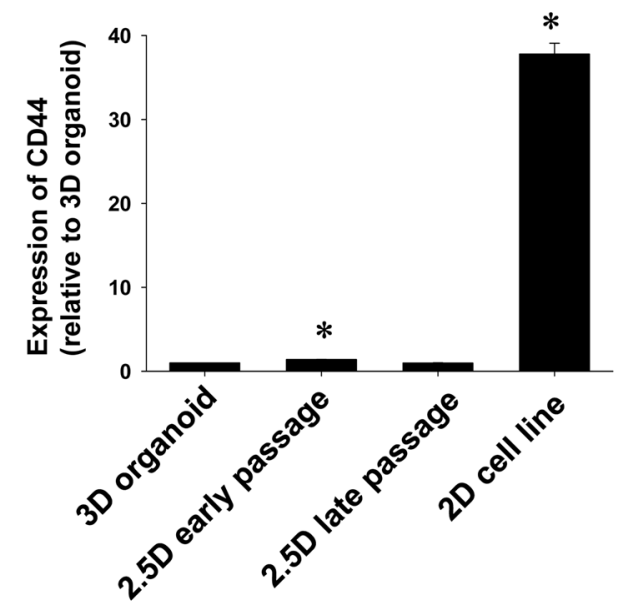

Figure 3. Comparison of cancer stem cell markers, SOX2 and CD44 between BC 2.5D organoid at the early and late passage and their original BC 3D organoids. Dog urothelial carcinoma cells were used as 2D cell lines. Expression level of SOX2 and CD44 in 3D and 2.5D organoids from different strains (BC1; A and BC2; B) and $2 \mathrm{D}$ cell lines was analyzed by quantitative real-time PCR $(n=4)$ and quantified based on the ratio of expression level to GAPDH. Data were expressed as mean \pm SEM. $* P<0.05$ vs. $3 \mathrm{D}$ organoid.

Response to anti-cancer drugs in BC 2.5D organoids. Since it was shown that dog BC 3D organoids can apply the anti-cancer drug sensitivity test in our previous study ${ }^{14}$, we compare the response to anti-cancer drugs between $2.5 \mathrm{D}$ organoids and their original 3D organoids. After $72 \mathrm{~h}$ treatment with different concentrations of a microtubule inhibitor, vinblastine, a topoisomerase inhibitor, mitoxantrone, and a DNA-damaging agent, carboplatin, the cell viability of $2.5 \mathrm{D}$ organoid cells at early and late passages decreased in a dose-dependent manner and showed a similar responsive profile to their original 3D organoids (Fig. 5A,B), suggesting that our established $2.5 \mathrm{D}$ organoids maintain the anti-cancer drug response profiles of their original $3 \mathrm{D}$ organoids and could be used for anti-cancer drug sensitivity test. 
A
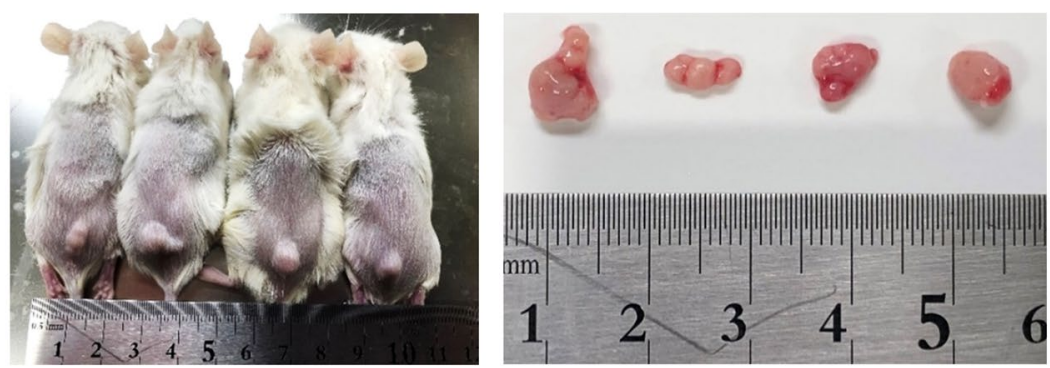

B
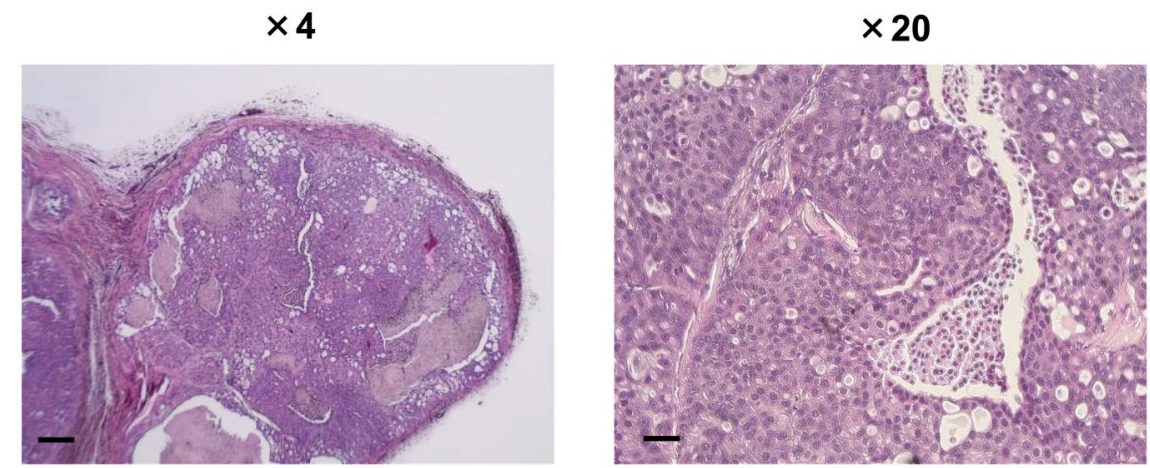

C
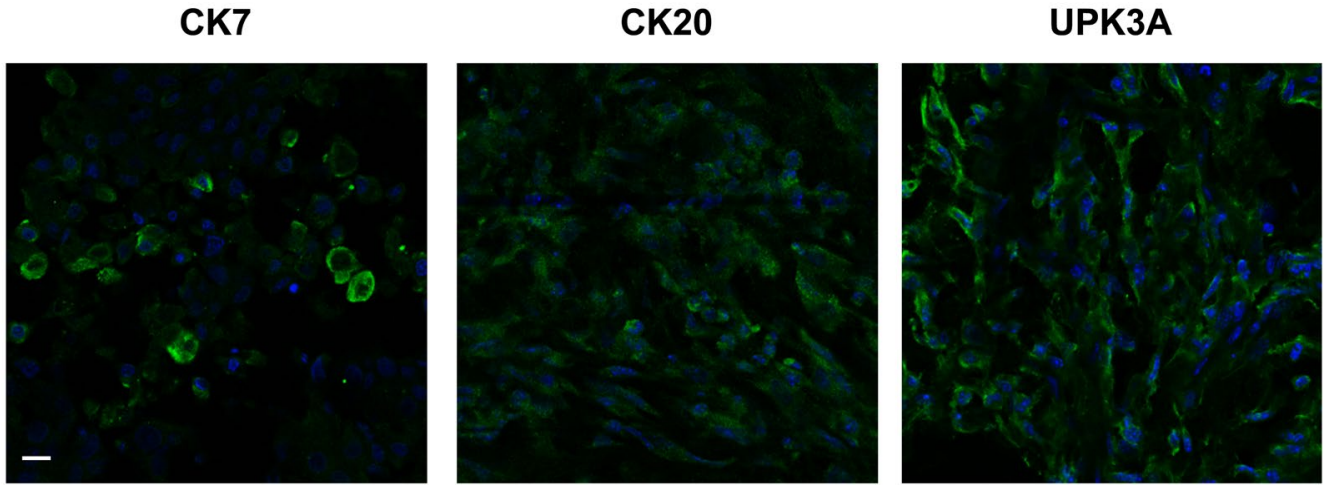

Figure 4. Tumorigenesis induced by BC $2.5 \mathrm{D}$ organoids. The trypsinized $2.5 \mathrm{D}$ cells $\left(1 \times 10^{6}\right)$ were subcutaneously injected into the back of NSG mice $(n=4)$. Six weeks later, the formed tumors were isolated and sectioned for $\mathrm{H} \& \mathrm{E}$ and immunofluorescence staining. Representative image of the formed tumors and their sizes (A). Representative images of $\mathrm{H} \& \mathrm{E}$ staining of the tumor tissue sections. The enlarged image is shown on the right. Scale bar: 500 and $100 \mu \mathrm{m}(\mathbf{B})$. Characterization of the cellular components of the formed tumors. Expression of CK7, CK20, and UPK3A in the tumor tissues (C). Representative photomicrographs were shown. Scale bar: $50 \mu \mathrm{m}$.

\section{Discussion}

In the current study, we for the first time established a new culture method of dog BC 2.5D organoids. These 2.5D organoids at even early and late passage maintained several characteristics of their parental 3D organoids. The main findings of the current study are as follows: (1) 2.5D organoid cells were successfully isolated from the different strains of 3D organoids by using our identified 2.5D organoid media (Fig. 1). (2) 2.5D organoids maintained the expression of urothelial cells markers, CK7, CK20, and UPK3A (Fig. 2A) and their proliferation speed was significantly higher than their parental 3D organoids (Fig. 2B). (3) Expression level of a cancer stem cell marker, SOX2 in 2.5D organoids was lower than 3D organoids but much higher than $2 \mathrm{D}$ urothelial carcinoma cell lines (Fig. 3). (4) Injection of 2.5D organoid cells into NSG mice successfully generated tumors (Fig. 4). (5) 2.5D organoids showed a similar response to anti-cancer drugs compared with their parental 3D organoids (Fig. 5). Collectively, our data indicate that $\operatorname{dog} \mathrm{BC} 2.5 \mathrm{D}$ organoids could be useful to investigate the mechanisms of dog $\mathrm{BC}$ and provide new insights for $\operatorname{dog} \mathrm{BC}$ therapy. 
A

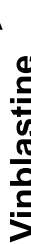

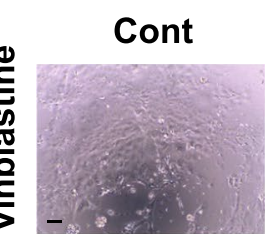

$0.01 \mathrm{nM}$

$0.1 \mathrm{nM}$

$n M$
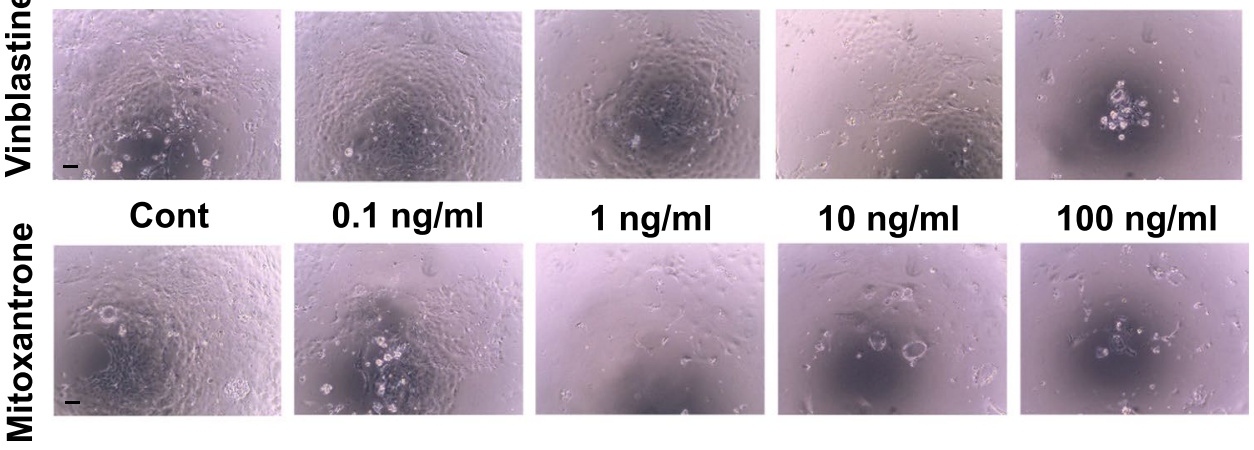

$0.1 \mathrm{ng} / \mathrm{ml}$

$1 \mathrm{ng} / \mathrm{ml}$

$10 \mathrm{ng} / \mathrm{ml}$

$100 \mathrm{ng} / \mathrm{ml}$
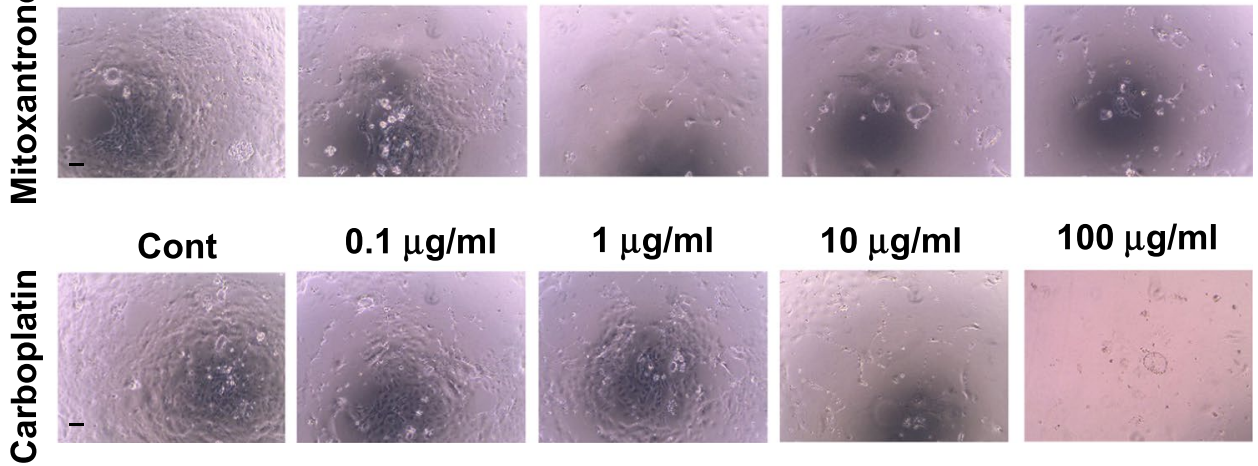

$0.1 \mu \mathrm{g} / \mathrm{ml}$

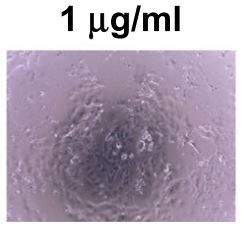

$10 \mu \mathrm{g} / \mathrm{ml}$

$100 \mu \mathrm{g} / \mathrm{ml}$
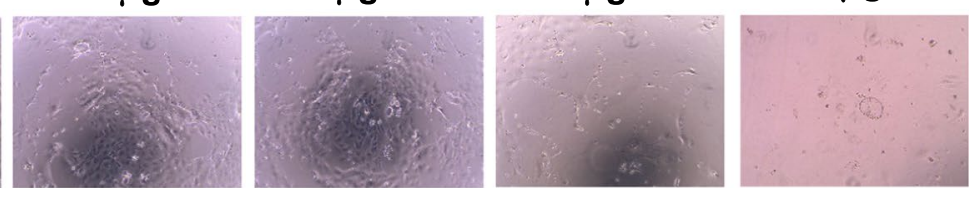

B

3D organoid $\bigcirc 2.5 \mathrm{D}$ early passage $\Delta 2.5 \mathrm{D}$ late passage
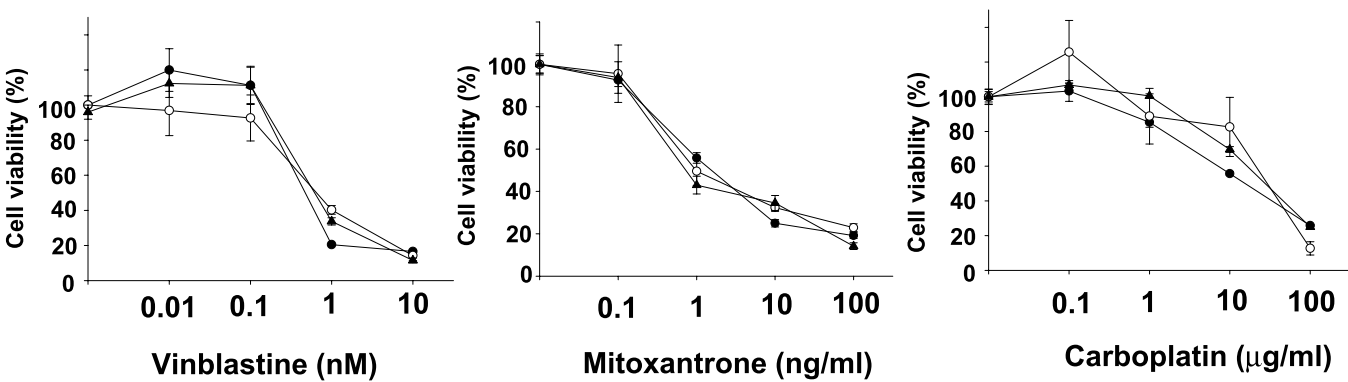

Figure 5. Comparison of the anti-cancer drug sensitivity between $\mathrm{BC} 2.5 \mathrm{D}$ organoids at the early and late passage and their original 3D organoids. After the 2.5D organoids were trypsinized and seeded into 96 well plates, they were treated with vinblastine, mitoxantrone, and carboplatin for $72 \mathrm{~h}$. Representative phase-contrast images of the treated 2.5D organoid cells at early passage were shown (A). Scale bar: $500 \mu \mathrm{m}$. Cell viability was assayed by the Prestoblue cell viability kit and $100 \%$ represents the cell viability of each control $(B, n=6)$. Data were presented as mean \pm S.E.M.

The 3D organoid culture models have become charming stuff for assaying cancer cell proliferation, differentiation, metabolism, tumor-stroma crosstalk, invasion, metastasis, and drug sensitivity screening ${ }^{17-21}$. The 3D culture system has thus gotten more attention as a tool to overcome the drawbacks of the 2D culture system for predicting the in vivo activities and by recapitulating the tumor microenvironment ${ }^{22}$. Although the $3 \mathrm{D}$ culture method has had a strong impact on the in vitro study of tumor biology and its therapeutic potential, it meets significant challenges. The Matrigel used in organoid culture is derived from animals with undefined hydrogel matrix compositions and has limited broad applications for the 3D organoid culture system in mechanistic and clinic-related studies besides its expensive cost and the long time it takes for seeding and growing the organoids. To overcome some of these limitations, researchers have focused back on 2D monolayer culture systems. Recently, Puca et al., named the cells derived from 3D prostate organoids as 2D organoids because the cells maintained the purity and genomic profile of their parental 3D organoids and also the original tumor tissues at serial timepoints with a concordant genome-wide copy number alteration ${ }^{23}$. In addition, in the previous published 2.5D organoid paper ${ }^{24}$, the cells were grown on top of a thick layer of ECM proteins such as Matrigel that allowed for tissue-specific differentiation of a variety of cells. Nevertheless, the culture system could not perfectly model the in vivo environment. Despite these limitations, $2.5 \mathrm{D}$ organoid assays are experimentally convenient and can induce cells to form a more physiological tissue architecture than conventional $2 \mathrm{D}$ cell culture systems. In the present study, we for the first time established a new gel-free culture method of dog BC cells, namely $2.5 \mathrm{D}$ organoid culture, that is considered as a phase between 2D and 3D. The cells were originally derived from their parental 3D organoids, cultured in special media that differ from organoid media, and grown rapidly and efficiently for several passages (Fig. 1). Since our established gel-free $2.5 \mathrm{D}$ organoid could recapitulate most of the characteristics of their parental 3D organoids, it is clearly different from previous models. Furthermore, our newly 
established method overcame the issues of high cost and long handling time of organoids. Therefore, we believe that our established method becomes a promising research model for studying patient-derived cancer cells.

The difference of the media components between the $2.5 \mathrm{D}$ and $3 \mathrm{D} \mathrm{BC}$ organoids was presented in Table 1 . The presence of $5 \%$ FBS and EGF in the 2.5D media promoted cell growth, migration, differentiation, and attachment to the bottom of culture dish ${ }^{25-27}$. Further, a TGF- $\beta$ inhibitor, A83-01, was added to prevent fibroblast proliferation. Additionally, the $2.5 \mathrm{D}$ organoid culture media do not contain the strong stemness-supporting supplements, such as Wnt, Noggin, and R-spondin contained in the 3D organoids culture media. Other supplements such as nicotinamide and $\mathrm{N}$-acetyl-L-cysteine were used to maintain the stemness. We suppose that these components are important for generating 2.5D BC organoid cells.

Characterization of the normal and neoplastic epithelium of the urinary bladder has been performed mainly using cytokeratins (especially CK7 and CK20) and UPK3A antibodies in human ${ }^{28}$ and $\operatorname{dogs}^{29}$. They are useful as diagnostic aids in carcinoma of the bladder and their co-existent metastasis ${ }^{14,29-31}$. Jiang et al. examined the expression of CK7 and CK20 in 26 primary and metastatic BC and found that all the samples were positive to CK7 while $46 \%$ showed positive reactivity to CK2 $0^{32}$. In other studies, the expression of CK20 in urothelial carcinomas was $29 \%{ }^{33}, 83 \%{ }^{34}, 89 \%,{ }^{35}$, and $97 \%{ }^{28}$. Interestingly, the urine RT-PCR assay of CK20 showed higher sensitivity and specificity for urothelial carcinoma ${ }^{36}$. UPK3A could be a highly specific marker for urothelial tumors in human primary and metastatic urothelial carcinomas ${ }^{37,38}$ as well as dog urothelial tumors ${ }^{29}$. Ramos-Vara et al. confirmed the expression of CK7, CK20, and UPK3A in normal dog urinary bladder and $72 \operatorname{dog}$ BC and found that UPK3A is a highly specific and sensitive marker for $\operatorname{dog} \mathrm{BC}$, detecting $91 \%$ of the examined cases ${ }^{29}$. In our previous study, these three markers were clearly expressed in several BC 3D organoids of dogs and their xenograft-derived tumor tissues ${ }^{14}$. In the present study, they were expressed in 2.5D organoid cells (Fig. 2A) and xenografted tumor tissues (Fig. 4C), indicating that our established method could maintain the urothelial cellular components of their parental 3D organoids and that $2.5 \mathrm{D}$ organoid cells mainly consist of urothelial carcinoma cells.

The aggressiveness and prognosis of tumors mainly depend on the population of cancer stem cells (CSCs), the self-renewing and differentiating cells that mediate resistance to chemotherapy ${ }^{39-45}$. CSCs are heterogeneous and composed of several phenotypes with different markers, which renders it extremely difficult to target in an individual patient. Therefore, identifying CSC-specific markers in each tumor is required for the establishment of tailored therapies ${ }^{46}$. Several CSC markers such as CD44, CD133, ALDH1, SOX2, EZH1, PD-L1, CD67LR, BCMab1, BMI1, MAGE-A3, and YAP $1^{44,47-49}$ were known to be expressed in BC. The transcription factor, SOX2 was found to be a CSC marker for both human and mouse BC and was absent in normal urothelial cells ${ }^{50}$. Additionally, SOX2 is associated with tumor progression and prognosis in urothelial carcinoma ${ }^{51,52}$. On the other hand, Chan et al. showed that $40 \%$ of more than $300 \mathrm{BC}$ samples contained $\mathrm{CD} 44^{+}$cells and were able to form tumors in vivo 10-200 times than CD44 cells in mice ${ }^{53}$. On the contrary, the CD44 $4^{+} / \mathrm{CD} 24^{-}$cells were associated with a better prognosis, indicating that this phenotype is not suitable for detecting CSCs in dog mammary carcinomas ${ }^{54}$. Nevertheless, there is no data showing the expression of CD44 or SOX2 mediates the tumor progression in dog urothelial carcinoma. In the present study, SOX2 was upregulated while CD44 was downregulated in dog BC 3D and $2.5 \mathrm{D}$ organoids compared with the $2 \mathrm{D}$ urothelial carcinoma cell lines (Fig. 3), suggesting that SOX2 is implicated in the progression and proliferation of $\mathrm{BC}$ in dogs by increasing the stemness and could be considered as a novel and reliable CSC marker in dog urothelial carcinoma.

The difference in the drug sensitivities between $2 \mathrm{D}$ and $3 \mathrm{D}$ culture conditions has been reported in different cancers $^{55,56}$, probably due to higher stemness and expression of multidrug resistance (MDR) proteins in the 3D conditions. In breast cancer, Imamura et al. assessed the difference in drug response between 2D and 3D culture of several breast cancer cell lines and primary cultured cells from a patient-derived xenograft and the patient's original tumor tissues. They found higher resistance to paclitaxel and doxorubicin in the 3D cultured cells compared with the 2D cultured ones, probably due to the decreased expression of cleaved-PARP, cleaved-caspase-3, and Ki-67, greater G0-dormant subpopulation, and hypoxic condition ${ }^{57}$. In BC, Myeong et al. showed that the effect of rapamycin and Bacillus Calmette-Guérin (BCG) was more exaggerated in the 2D cell culture than that in the $3 \mathrm{D}$ cell culture environment ${ }^{58}$. Additionally, RT4 cells, a $\mathrm{BC}$ cell line cultured under $3 \mathrm{D}$ conditions also showed higher resistance to doxorubicin compared with 2D cultures ${ }^{59}$. On the other hand, our established 2.5D organoids showed similar responses to anti-cancer drug treatment compared with 3D organoids. Since the trend of stem cell marker expressions in $2.5 \mathrm{D}$ organoid cells is more close to $3 \mathrm{D}$ organoid ones compared with $2 \mathrm{D}$ cell lines as shown in Fig. 3, it might cause the similar response to anti-cancer drugs. Nevertheless, further research is necessary for using $2.5 \mathrm{D}$ organoid cells instead of 3D organoids.

\section{Conclusion}

We for the first-time generated BC 2.5D organoids from 3D organoids. These 2.5D organoids showed constant passages and higher proliferation speed than their parental 3D organoids. The $2.5 \mathrm{D}$ organoids demonstrated the tumorigenesis in vivo and maintained the expression pattern of urothelial and bladder CSC markers. Furthermore, the $2.5 \mathrm{D}$ organoids showed a similar response to anti-cancer drugs with their parental $3 \mathrm{D}$ organoids. These results suggest that our established gel-free 2.5D culture method can be used as a cheaper and less time-consumed research model instead of $3 \mathrm{D}$ organoid studies to investigate the mechanisms of $\mathrm{BC}$ diseased dogs. It also provides new insights into the development of dog BC therapy.

\section{Data availability}

The authors declare that all data supporting the findings of this study are available within the article.

Received: 11 December 2019; Accepted: 18 May 2020;

Published online: 10 June 2020 


\section{References}

1. Fulkerson, C. M. \& Knapp, D. W. Management of transitional cell carcinoma of the urinary bladder in dogs: a review. Vet J 205, 217-225, https://doi.org/10.1016/j.tvjl.2015.01.017 (2015).

2. Knapp, D. W. \& McMillan, S. K. In Small Animal Clinical Oncology (ed Withrow \& MacEwen's) 572-582 (LouisElsevier-Saunders, 2013).

3. Lerner, S. P., Schoenberg, M. P. \& Sternberg, C. N. Textbook of Bladder Cancer. (Taylor and Francis, 2006).

4. Patrick, D. J., Fitzgerald, S. D., Sesterhenn, I. A., Davis, C. J. \& Kiupel, M. Classification of canine urinary bladder urothelial tumours based on the World Health Organization/International Society of Urological Pathology consensus classification. Journal of comparative pathology 135, 190-199, https://doi.org/10.1016/j.jcpa.2006.07.002 (2006).

5. Valli, V. E. et al. Pathology of canine bladder and urethral cancer and correlation with tumour progression and survival. Journal of comparative pathology 113, 113-130, https://doi.org/10.1016/s0021-9975(05)80027-1 (1995).

6. Mutsaers, A. J., Widmer, W. R. \& Knapp, D. W. Canine transitional cell carcinoma. Journal of veterinary internal medicine 17, 136-144, 10.1892/0891-6640(2003)017<0136:ctcc >2.3.co;2 (2003).

7. Knapp, D. In Textbook of Bladder Cancer. (eds S. Lerner, M. Schoenberg, \& C. Sternberg) 171-175. (Taylor and Francis, 2006).

8. Dhawan, D., Ramos-Vara, J. A., Stewart, J. C., Zheng, R. \& Knapp, D. W. Canine invasive transitional cell carcinoma cell lines: in vitro tools to complement a relevant animal model of invasive urinary bladder cancer. Urologic oncology 27, 284-292, https://doi. org/10.1016/j.urolonc.2008.02.015 (2009).

9. Arantes-Rodrigues, R., Colaco, A., Pinto-Leite, R. \& Oliveira, P. A. In vitro and in vivo experimental models as tools to investigate the efficacy of antineoplastic drugs on urinary bladder cancer. Anticancer research 33, 1273-1296 (2013).

10. Oliveira, P. A., Arantes-Rodrigues, R. \& Vasconcelos-Nobrega, C. Animal models of urinary bladder cancer and their application to novel drug discovery. Expert opinion on drug discovery 9, 485-503, https://doi.org/10.1517/17460441.2014.902930 (2014).

11. Kobayashi, T., Owczarek, T. B., McKiernan, J. M. \& Abate-Shen, C. Modelling bladder cancer in mice: opportunities and challenges. Nature reviews. Cancer 15, 42-54, https://doi.org/10.1038/nrc3858 (2015).

12. Bartfeld, S. \& Clevers, H. Stem cell-derived organoids and their application for medical research and patient treatment. Journal of molecular medicine (Berlin, Germany) 95, 729-738, https://doi.org/10.1007/s00109-017-1531-7 (2017).

13. Takahashi, T. Organoids for Drug Discovery and Personalized Medicine. Annual review of pharmacology and toxicology 59, 447-462, https://doi.org/10.1146/annurev-pharmtox-010818-021108 (2019).

14. Elbadawy, M. et al. Establishment of a novel experimental model for muscle-invasive bladder cancer using a dog bladder cancer organoid culture. Cancer science 110, 2806-2821, https://doi.org/10.1111/cas.14118 (2019).

15. Usui, T. et al. Establishment of a dog primary prostate cancer organoid using the urine cancer stem cells. Cancer science 108, 2383-2392, https://doi.org/10.1111/cas.13418 (2017).

16. Ramakrishnan, S. et al. Transcriptional changes associated with in vivo growth of muscle-invasive bladder cancer cell lines in nude mice. Am J Clin Exp Urol 6, 138-148 (2018).

17. Hirschhaeuser, F. et al. Multicellular tumor spheroids: an underestimated tool is catching up again. Journal of biotechnology 148, 3-15, https://doi.org/10.1016/j.jbiotec.2010.01.012 (2010).

18. Rudisch, A. et al. High EMT Signature Score of Invasive Non-Small Cell Lung Cancer (NSCLC) Cells Correlates with NFkappaB Driven Colony-Stimulating Factor 2 (CSF2/GM-CSF) Secretion by Neighboring Stromal Fibroblasts. PLoS One 10, e0124283, https://doi.org/10.1371/journal.pone.0124283 (2015).

19. Usui, T., Elbadawy, M. \& Sasaki, K. Session 6: Advances in Anticancer Therapy. Journal of Veterinary Pharmacology and Therapeutics 41, 28-30, https://doi.org/10.1111/jvp.12625 (2018).

20. Elbadawy, M. et al. Efficacy of primary liver organoid culture from different stages of non-alcoholic steatohepatitis (NASH) mouse model. Biomaterials 237, 119823, https://doi.org/10.1016/j.biomaterials.2020.119823 (2020).

21. Abugomaa, A. \& Elbadawy, M. Patient-derived organoid analysis of drug resistance in precision medicine: is there a value? Expert Review of Precision Medicine and Drug Development 5, 1-5, https://doi.org/10.1080/23808993.2020.1715794 (2020).

22. Debnath, J. \& Brugge, J. S. Modelling glandular epithelial cancers in three-dimensional cultures. Nature reviews. Cancer 5, 675-688, https://doi.org/10.1038/nrc1695 (2005).

23. Puca, L. et al. Patient derived organoids to model rare prostate cancer phenotypes. Nat Commun 9, 2404, https://doi.org/10.1038/ s41467-018-04495-z (2018).

24. Shamir, E. R. \& Ewald, A. J. Three-dimensional organotypic culture: experimental models of mammalian biology and disease. Nat Rev Mol Cell Biol 15, 647-664, https://doi.org/10.1038/nrm3873 (2014).

25. Izumi, K., Zheng, Y., Li, Y., Zaengle, J. \& Miyamoto, H. Epidermal growth factor induces bladder cancer cell proliferation through activation of the androgen receptor. Int J Oncol 41, 1587-1592, https://doi.org/10.3892/ijo.2012.1593 (2012).

26. Fang, C. Y., Wu, C. C., Fang, C. L., Chen, W. Y. \& Chen, C. L. Long-term growth comparison studies of FBS and FBS alternatives in six head and neck cell lines. PLoS One 12, e0178960, https://doi.org/10.1371/journal.pone.0178960 (2017).

27. Omar Zaki, S. S., Kanesan, L., Leong, M. Y. D. \& Vidyadaran, S. The influence of serum-supplemented culture media in a transwell migration assay. Cell Biol Int 43, 1201-1204, https://doi.org/10.1002/cbin.11122 (2019).

28. Moll, R., Lowe, A., Laufer, J. \& Franke, W. W. Cytokeratin 20 in human carcinomas. A new histodiagnostic marker detected by monoclonal antibodies. The American journal of pathology 140, 427-447 (1992).

29. Ramos-Vara, J. A., Miller, M. A., Boucher, M., Roudabush, A. \& Johnson, G. C. Immunohistochemical detection of uroplakin III, cytokeratin 7, and cytokeratin 20 in canine urothelial tumors. Veterinary pathology 40, 55-62, https://doi.org/10.1354/vp.40-1-55 (2003).

30. Miettinen, M. Keratin 20: immunohistochemical marker for gastrointestinal, urothelial, and Merkel cell carcinomas. Modern pathology: an official journal of the United States and Canadian Academy of Pathology, Inc 8, 384-388 (1995).

31. Ramaekers, F. et al. Use of monoclonal antibodies to keratin 7 in the differential diagnosis of adenocarcinomas. The American journal of pathology 136, 641-655 (1990).

32. Jiang, J. et al. Cytokeratin 7 and cytokeratin 20 in primary urinary bladder carcinoma and matched lymph node metastasis. Archives of pathology \& laboratory medicine 125, 921-923, 10.1043/0003-9985(2001)125<0921:CACIPU >2.0.CO;2 (2001).

33. Chu, P., Wu, E. \& Weiss, L. M. Cytokeratin 7 and cytokeratin 20 expression in epithelial neoplasms: a survey of 435 cases. Modern pathology: an official journal of the United States and Canadian Academy of Pathology, Inc 13, 962-972, https://doi.org/10.1038/ modpathol.3880175 (2000).

34. Bassily, N. H., Vallorosi, C. J., Akdas, G., Montie, J. E. \& Rubin, M. A. Coordinate expression of cytokeratins 7 and 20 in prostate adenocarcinoma and bladder urothelial carcinoma. Am J Clin Pathol 113, 383-388, https://doi.org/10.1309/G1RA-EU9X-X6VV$3 \mathrm{~W} 79$ (2000).

35. Wang, N., Zee, S., Zarbo, R., Bacchi, C. \& Gown, A. Coordinate expression of cytokeratins 7 and 20 defines unique subsets of carcinomas. Applied immunohistochemistry 3, 99-107 (1995).

36. Mi, Y. et al. Diagnostic accuracy of urine cytokeratin 20 for bladder cancer: A meta-analysis. Asia-Pacific journal of clinical oncology 15, e11-e19, https://doi.org/10.1111/ajco.13024 (2019)

37. Moll, R., Laufer, J., Wu, X. R. \& Sun, T. T. [Uroplakin III, a specific membrane protein of urothelial umbrella cells, as a histological markers for metastatic transitional cell carcinomas]. Verhandlungen der Deutschen Gesellschaft fur Pathologie 77, 260-265 (1993). 
38. Kaufmann, O., Volmerig, J. \& Dietel, M. Uroplakin III is a highly specific and moderately sensitive immunohistochemical marker for primary and metastatic urothelial carcinomas. Am J Clin Pathol 113, 683-687, https://doi.org/10.1309/PYQC-17CB-063T-Q07J (2000).

39. Usui, T. et al. Establishment of a Novel Model for Anticancer Drug Resistance in Three-Dimensional Primary Culture of Tumor Microenvironment. Stem Cells Int 2016, 7053872, https://doi.org/10.1155/2016/7053872 (2016).

40. Codony-Servat, J. \& Rosell, R. Cancer stem cells and immunoresistance: clinical implications and solutions. Translational lung cancer research 4, 689-703, https://doi.org/10.3978/j.issn.2218-6751.2015.12.11 (2015).

41. Usui, T. et al. Hedgehog Signals Mediate Anti-Cancer Drug Resistance in Three-Dimensional Primary Colorectal Cancer Organoid Culture. International journal of molecular sciences 19, 1098, https://doi.org/10.3390/ijms19041098 (2018).

42. Elbadawy, M., Usui, T., Yamawaki, H. \& Sasaki, K. Development of an Experimental Model for Analyzing Drug Resistance in Colorectal Cancer. Cancers (Basel) 10, 164, https://doi.org/10.3390/cancers10060164 (2018)

43. Elbadawy, M., Usui, T., Yamawaki, H. \& Sasaki, K. Emerging Roles of C-Myc in Cancer Stem Cell-Related Signaling and Resistance to Cancer Chemotherapy: A Potential Therapeutic Target Against Colorectal Cancer. International journal of molecular sciences 20, 2340, https://doi.org/10.3390/ijms20092340 (2019).

44. Abugomaa, A., Elbadawy, M., Yamawaki, H., Usui, T. \& Sasaki, K. Emerging Roles of Cancer Stem Cells in Bladder Cancer Progression, Tumorigenesis, and Resistance to Chemotherapy: A Potential Therapeutic Target for Bladder. Cancer. Cells 9, 235, https://doi.org/10.3390/cells9010235 (2020).

45. Elbadawy, M., Abugomaa, A., Yamawaki, H., Usui, T. \& Sasaki, K. Development of Prostate Cancer Organoid Culture Models in Basic Medicine and Translational Research. Cancers (Basel) 12, 777, https://doi.org/10.3390/cancers12040777 (2020).

46. Ramos, E. K., Hoffmann, A. D. \& Gerson, S. L. \& Liu, H. New Opportunities and Challenges to Defeat Cancer Stem Cells. Trends in cancer 3, 780-796, https://doi.org/10.1016/j.trecan.2017.08.007 (2017).

47. Liu, J. Y. et al. Overexpression of YAP 1 contributes to progressive features and poor prognosis of human urothelial carcinoma of the bladder. BMC cancer 13, 349, https://doi.org/10.1186/1471-2407-13-349 (2013).

48. Li, Y. et al. Bladder cancer stem cells: clonal origin and therapeutic perspectives. Oncotarget 8, 66668-66679, https://doi. org/10.18632/oncotarget.19112 (2017).

49. Fang, D. \& Kitamura, H. Cancer stem cells and epithelial-mesenchymal transition in urothelial carcinoma: Possible pathways and potential therapeutic approaches. International journal of urology: official journal of the Japanese Urological Association 25, 7-17, https://doi.org/10.1111/iju.13404 (2018).

50. Zhu, F. et al. SOX2 Is a Marker for Stem-like Tumor Cells in Bladder Cancer. Stem cell reports 9, 429-437, https://doi.org/10.1016/j. stemcr.2017.07.004 (2017).

51. Kitamura, H. et al. Prognostic impact of the expression of ALDH1 and SOX2 in urothelial cancer of the upper urinary tract. Modern pathology: an official journal of the United States and Canadian Academy of Pathology, Inc 26, 117-124, https://doi.org/10.1038/ modpathol.2012.139 (2013).

52. Ruan, J. et al. Predictive value of Sox 2 expression in transurethral resection specimens in patients with T1 bladder cancer. Medical oncology (Northwood, London, England) 30, 445, https://doi.org/10.1007/s12032-012-0445-z (2013).

53. Chan, K. S. et al. Identification, molecular characterization, clinical prognosis, and therapeutic targeting of human bladder tumorinitiating cells. Proceedings of the National Academy of Sciences of the United States of America 106, 14016-14021, https://doi. org/10.1073/pnas.0906549106 (2009).

54. Rogez, B. et al. CD44 and CD24 Expression and Prognostic Significance in Canine Mammary Tumors. Veterinary pathology 56, 377-388, https://doi.org/10.1177/0300985818813653 (2019).

55. Deiss, F. et al. Platform for high-throughput testing of the effect of soluble compounds on 3D cell cultures. Analytical chemistry 85, 8085-8094, https://doi.org/10.1021/ac400161j (2013).

56. Weigelt, B., Lo, A. T., Park, C. C., Gray, J. W. \& Bissell, M. J. HER2 signaling pathway activation and response of breast cancer cells to HER2-targeting agents is dependent strongly on the 3D microenvironment. Breast cancer research and treatment 122, 35-43, https:// doi.org/10.1007/s10549-009-0502-2 (2010).

57. Imamura, Y. et al. Comparison of 2D- and 3D-culture models as drug-testing platforms in breast cancer. Oncology reports 33, 1837-1843, https://doi.org/10.3892/or.2015.3767 (2015).

58. Kim, M. J. et al. Structure establishment of three-dimensional (3D) cell culture printing model for bladder cancer. PLoS One 14, e0223689, https://doi.org/10.1371/journal.pone.0223689 (2019).

59. Amaral, R. L. F., Miranda, M., Marcato, P. D. \& Swiech, K. Comparative Analysis of 3D Bladder Tumor Spheroids Obtained by Forced Floating and Hanging Drop Methods for Drug Screening. Front Physiol 8, 605, https://doi.org/10.3389/fphys.2017.00605 (2017).

\section{Author contributions}

Amira Ibrahim, Mohamed Elbadawy, Megumi Yamanaka, Yuta Goto, and Kimika Hayashi carried out the experiment. Takashi Mori, Tsuyoshi Uchide, Daigo Azakami, and Ryuji Fukushima provided clinical samples. Toshinori Yoshida, Makoto Shibutani, Mio Kobayashi and Risako Yamashita performed pathological experiments. Mohamed Elbadawy, Hideyuki Yamawaki, Yuta Shinohara, Masahiro Kaneda, Tatsuya Usui, and Kazuaki Sasaki designed study, analyzed, and interpreted the data, and wrote manuscript.

\section{Competing interests}

The authors declare no competing interests.

\section{Additional information}

Correspondence and requests for materials should be addressed to T.U.

Reprints and permissions information is available at www.nature.com/reprints.

Publisher's note Springer Nature remains neutral with regard to jurisdictional claims in published maps and institutional affiliations. 
(c) (i) Open Access This article is licensed under a Creative Commons Attribution 4.0 International License, which permits use, sharing, adaptation, distribution and reproduction in any medium or format, as long as you give appropriate credit to the original author(s) and the source, provide a link to the Creative Commons license, and indicate if changes were made. The images or other third party material in this article are included in the article's Creative Commons license, unless indicated otherwise in a credit line to the material. If material is not included in the article's Creative Commons license and your intended use is not permitted by statutory regulation or exceeds the permitted use, you will need to obtain permission directly from the copyright holder. To view a copy of this license, visit http://creativecommons.org/licenses/by/4.0/.

(C) The Author(s) 2020 